\title{
reviews
}

HERE is a book that should immediately be put into paperback and placed in the hands of undergraduates everywhere and in all disciplines. Its subject matter ranges from the cathedral builders of the Middle Ages to the prophets of systems analysis in our own century. Yet Dr Pacey is nowhere superficial. His discussion of "A century of invention: 1250-1350" includes, for example, an exciting examination of the thesis that the weight-driven clock was not the product of monastic needs but was inspired by the imaginative desire to parallel the movements of the planets in a model here below. The author constantly stresses non-economic motivation in the development of technology and, in this respect, seems to share a point of view with that great historian of metallurgy, C. S. Smith, whose work he never cites. It is very refreshing, moreover, to see a history of technology that refers truly to the technology of Asia (China, India and Japan) as well as that of the West, and moves with confidence in discussing the Islamic contributions to mediaeval and renaissance technology. One chapter is entitled "The effects of mechanisation in Europe and Asia: trends in technology between 1810 and 1870".

Though Dr Pacey is best known for papers on various aspects of the Industrial Revolution in Britain, it is in his discussion of mediaeval and ren-

\section{Weighted clocks and steam engines}

\section{Eric H. Robinson}

The Maze of Ingenuity: Ideas and Idealism in the Development of Technology. By Arnold Pacey. Pp. 350. (Allen Lane: London, January 1975.) $£ 5.50$.

naissance architecture that he excels in this book. Not that he does not have illuminating comments on John Smeaton, James Watt, Peter Ewart, William Strutt and other well known figures of the late eighteenth and early nineteenth centuries; but his discussion flows most freely when he is not too closely involved with biographical detail. The book seems to be more concerned with broad imaginative ideals within different cultures and with the state of craftsmanship in different civilisations than it is with the heroic inventor, yet the biographical approach has a strong hold upon the author and sometimes seems to run away with him. On occasion, indeed, it seems to lead to self-contradiction. For example, on page 226 , Dr Pacey quotes from a letter by George
Lee to illustrate "the abysmal ignorance of algebra and the calculus which prevailed among even well-read engineers in Britain at this time" but on page 240 quotes with approval Robert Owen's judgment of Lee as "one of the most scientific men of his day, who was considered a man of very superior attainments, having been highly educated, and being a finished mathematician".

I would question in particular Dr Pacey's evaluation of some eminent technologists, but found the book constantly illuminating, soundly researched, ranging widely over different disciplines and always civilised in tone. How many historians of technology could be expected to comment with insight upon the poetry of Alexander Pope? Dr Pacey, however, is wrong in drawing a contrast between Britain's economically-motivated uses of the steam engine for mills and the Russian or French use of it to water gardens. One of the first uses of the Boulton and Watt steam engine in Britain was to water a landed gentleman's garden, and if you are pumping water you may as well use it to refresh your carnations or your cabbages as to drive a loom or power a brewery. In fact some of Dr Pacey's differentiations between technology motivated by ideals and technology motivated by gain are a little too simplistic but this is the best book on the history of technology over a wide period to appear for a long time.
THis book results from an Interdisciplinary conference on amniotic fluid held in May 1973, under the auspices of the American Association of Clinical Chemists, and the Chicago Gynaecological, Immunological and Paediatric Societies. Each session is represented by a section of the book.

Section 1 includes papers on the morphology and development of the amnion, and the dynamics and chemistry of the amniotic fluid. The latter is concerned mainly with a consideration of the commoner metabolites although there is a report of recent work on measurements of adrenalin and noradrenalin.

Section 2 includes papers on immunoglobulins and other protein constituents of amniotic fluid, electrophoretic and immunological analysis of amniotic fluid, placental lactogen, disseminated intravascular coagulation in obstetrics, and papers dealing with problems arising from Rhesus incom-

\section{Amniotic fluid}

\section{R. W. E. Watts}

Amniotic Fluid: Physiology, Biochemistry and Clinical Chemistry. (Current Topics in Clinical Chemistry, vol. 1.) Edited by Samuel Natelson, Antonio Scommegna and Morton B. Epstein. Pp. $x v+386$. (Wiley: New York and London, 1974.) $£ 10.80$.

patibility. Section 3 deals with the obstetrical problems such as the technique of amniocentesis, use of ultrasonography, the value of lecithin, sphingomyelin and oestrogen measurements in clinical practice.

The last section deals with the very rapidly growing field of the diagnosis of genetic disorders, and there have been new developments even in the small range of topics covered since the conference was held. Newton
Ressler's contribution discusses a pitfall which must be avoided in this work and it should be read carefully by anyone entering the field. Abraham Saifer and his colleagues describe their extensive experience of mass screening for heterozygous carriers of Tay Sachs disease, and in the prenatal diagnosis of this disorder. This chapter is of particular interest as a pointer to what can be achieved when necessary in this area of preventive medicine.

The book contains much of interest to biochemists and clinicians, but it is patchy and uneven in coverage and in style. Some of the contributions would have profited from more severe editing so that they less obviously resembled a transcript of the spoken contribution. Regrettably, a few of the papers contain mainly material which is already well known. It is, however, a useful book for the specialist and for the library. 